\title{
Convergence of Theory and Experiment on the Role of Preorganization, Quantum Tunneling, and Enzyme Motions into Flavoenzyme-Catalyzed Hydride Transfer
} DOI:

10.1021/acscatal.7b00201

\section{Document Version}

Accepted author manuscript

Link to publication record in Manchester Research Explorer

Citation for published version (APA):

Delgado, M., Gorlich, S., Longbotham, J. E., Scrutton, N., Hay, S., Moliner, V., \& Tuñón, I. (2017). Convergence of Theory and Experiment on the Role of Preorganization, Quantum Tunneling, and Enzyme Motions into Flavoenzyme-Catalyzed Hydride Transfer. ACS Catalysis, 7, 3190-3198. https://doi.org/10.1021/acscatal.7b00201

Published in:

ACS Catalysis

\section{Citing this paper}

Please note that where the full-text provided on Manchester Research Explorer is the Author Accepted Manuscript or Proof version this may differ from the final Published version. If citing, it is advised that you check and use the publisher's definitive version.

\section{General rights}

Copyright and moral rights for the publications made accessible in the Research Explorer are retained by the authors and/or other copyright owners and it is a condition of accessing publications that users recognise and abide by the legal requirements associated with these rights.

\section{Takedown policy}

If you believe that this document breaches copyright please refer to the University of Manchester's Takedown Procedures [http://man.ac.uk/04Y6Bo] or contact uml.scholarlycommunications@manchester.ac.uk providing relevant details, so we can investigate your claim.

\section{OPEN ACCESS}




\title{
Convergence of theory and experiment on the role of preorganization, quantum tunneling and enzyme motions into flavoenzyme-catalyzed hydride transfer
}

Manuel Delgado, ${ }^{\dagger, \#}$ Stefan Görlich, ${ }^{\ddagger, \#}$ James E. Longbotham, ${ }^{\ddagger}$ Nigel S. Scrutton, ${ }^{\ddagger}$ Sam Hay, ${ }^{\ddagger} *$ Vicent Moliner, ${ }^{\dagger} ¥, *$ Iñaki Tuñón, ${ }^{\S} * *$

†Department of Physical and Analytical Chemistry, University Jaume I, 12071, Castelló de la Plana, Spain

${ }^{*}$ Manchester Institute of Biotechnology and School of Chemistry, The University of Manchester, 131 Princess Street, Manchester, M1 7DN, United Kingdom.

'Current address: Department of Cellular and Molecular Pharmacology, University of California San Francisco, San Francisco, CA 94158-2140.

${ }^{\S}$ Department of Physical Chemistry, University of València, 46100, Burjassot, Spain.

¥ Department of Chemistry, University of Bath, Bath BA2 7AY, United Kingdom.

${ }^{\#}$ These authors contributed equally.

\begin{abstract}
Hydride transfer is one of the most common reactions catalyzed by enzymatic systems and it has become an object of study due to possible significant quantum tunneling effects. In the present work, we provide a combination of theoretical QM/MM simulations and experimental measurements of the rate constants and kinetic isotopic effects (KIEs) for the hydride transfer reaction catalyzed by morphinone reductase, MR. Quantum mechanical tunneling coefficients, computed in the framework of variational transition-state theory, play a significant role in this reaction, reaching values of $23.8 \pm$ 5.5 for the lightest isotopologue; one of the largest values reported for enzymatic systems. This prediction is supported by the agreement between the theoretically predicted rate constants and the corresponding experimental values. Simulations indicate that the role of protein motions can be satisfactorily described as equilibrium
\end{abstract}


fluctuations along the reaction coordinate, in line with a high degree of preorganization displayed by this enzyme.

KEYWORDS: Morphinone Reductase, QM/MM, molecular dynamics, Kinetic Isotope Effects, Hydride transfer

\section{Introduction}

One of the most controversial subjects in modern enzymology is the role of dynamic effects in the enzymatic catalysis, especially in the case where dynamics are thought to facilitate quantum mechanical tunneling (QMT). It is well known that the flexibility of proteins allows them to adapt their three-dimensional conformation to each step of the catalytic process, such as substrate binding or product release. When the rate constant of the chemical step is considered, especially when light particles such as hydrogen atoms are involved in this step, then the debate is whether dynamic effects have a contribution to catalysis. ${ }^{1-4}$ Broadly, two theories have been postulated to explain the catalytic potential of enzymes. Some authors suggest that there are specific protein motions

coupled to $\mathrm{H}$ (proton, hydrogen atom or hydride ion) transfer. ${ }^{3,5}$ These protein motions might reduce the height and/or width of the potential energy barrier, being the driving force of enzymatic reactions. ${ }^{3,5}$ These studies base their arguments in the strong temperature and/or pressure dependence of experimental kinetic isotope effects (KIEs), which are thought to arise through thermally activated protein motions that would reduce the apparent barrier height and/or width. However, this hypothesis remains contentious, as there is no definitive experimental technique that can directly deduce the connection between promoting motions and the shape of the reaction barrier. Alternatively, many studies have shown that enzyme catalysis is dominated by transition state (TS) stabilization relative to the reactant state (RS). ${ }^{6-154,6-13}$ This reduction in activation free energy, which is an equilibrium property, directly leads to an increase in reaction rate and can explain the source of catalytic power of many enzymes. This model also takes into account protein motions by describing them as equilibrium fluctuations around the TS. In fact, most of the debate can be recast in terms of which are the relevant coordinates needed to define the dynamic bottleneck and the importance of tunneling for the determination of the rate constant. ${ }^{14-16}$ 
Morphinone reductase (MR) is an Old Yellow flavoenzyme, which catalyzes a hydride transfer from the $\mathrm{C} 4$ of nicotinamide adenine dinucleotide (NADH) to the $\mathrm{N} 5$ atom of a bound flavin mononucleotide (FMN) cofactor (Scheme 1). This reaction has been extensively experimentally and computationally characterized in $\mathrm{MR}^{17-23}$ and closely homologous enzymes. ${ }^{21,22,24}$ Unusually, $1^{\circ}, 2^{\circ}$ and double KIEs (Scheme 1) on hydride transfer have all been previously measured ${ }^{21}$ and calculated, ${ }^{19}$ making this an excellent model system of enzyme catalyzed H-transfers. However, the magnitude of the experimentally observed $1^{\circ}$ and double KIEs were subsequently found to be underestimated due to isotopic (protium) contamination of the NADH isotopologues used. ${ }^{25}$ Further, the computational study is unusual as it suggested the reaction proceeds via a "deep" QMT mechanism, ${ }^{19}$ with a much larger QMT contribution than many other comparable enzymes. The present work contains new experimental and computational results, which together give further insight into the reaction and suggest that the role of QMT of the transferred hydride during the reaction is less significant than previously thought. As shown in this work, MR is an excellent system to evaluate the impact of tunneling in the rate constant and KIEs, paving the way for future studies on the role of tunneling during the evolution of a specific enzymatic activity.

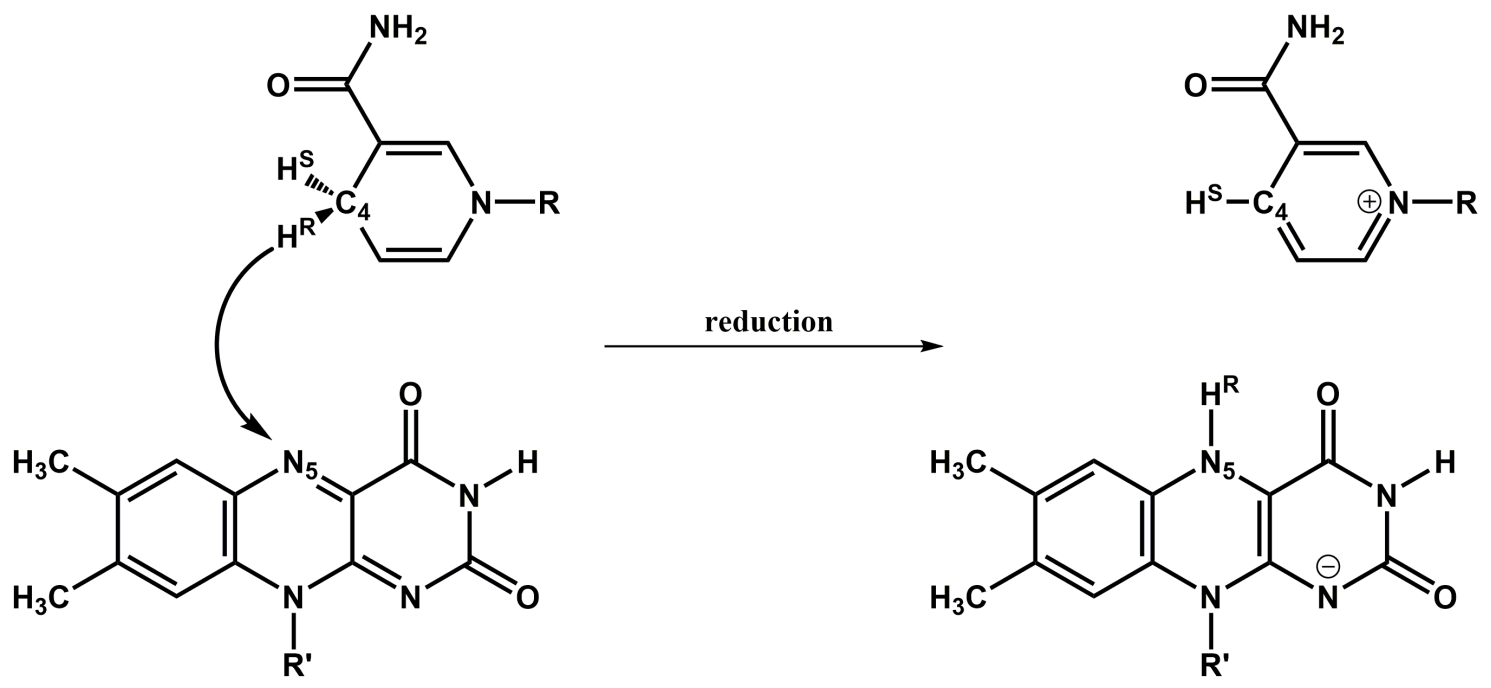

Scheme 1. Schematic representation of the hydride transfer from NADH to FMN during the reductive half reaction catalyzed by MR. $1^{\circ}, 2^{\circ}$ and double KIEs arise when $\mathrm{H}^{\mathrm{R}}, \mathrm{H}^{\mathrm{S}}$ and both $\mathrm{H}^{\mathrm{R}}$ and $\mathrm{H}^{\mathrm{S}}$ are isotopically labeled (DH, HD and DD isotopologues, respectively). 


\section{Methodology}

Experimental. All materials were obtained from Sigma-Aldrich (St. Louis, MO), except $\mathrm{NAD}^{+}$and $\mathrm{NADH}$, which were obtained from Melford Laboratories (Chelsworth, U.K.) MR was expressed and purified as described previously. ${ }^{21}(R)-[4-$ $\left.{ }^{2} \mathrm{H}\right]-\mathrm{NADH}$ and $(S)-\left[4-{ }^{2} \mathrm{H}\right]-\mathrm{NADH}$ were prepared as described previously. ${ }^{26}(R, S)-[4-$ ${ }^{2} \mathrm{H}_{2}$ ]-NADH was prepared in a one-pot synthesis by stereospecific oxidation of $250 \mathrm{mg}$ $\mathrm{NAD}^{+}$using $200 \mathrm{U}$ glucose dehydrogenase and $80 \mathrm{mg} 1-\left[{ }^{2} \mathrm{H}\right]$-glucose in $20 \mathrm{ml}$ of 25 $\mathrm{mM} \mathrm{NH} \mathrm{NCO}_{3} \mathrm{pH} 8.5$. The $\mathrm{pH}$ of the buffered solution was adjusted to $\mathrm{pH} 8.5 \mathrm{using}$ liquid ammonia. After the absorbance ratio of 260:340 reached $\sim 2.3,2 \mathrm{~mL}$ of $120 \mu \mathrm{M}$ of His-tagged MR and $50 \mathrm{mM}$ 2-cyclohexenone were added to the solution. The $\mathrm{pH}$ of the buffered solution was adjusted to $\mathrm{pH} 8.0$ using liquid formic acid. After the absorbance at $340 \mathrm{~nm}$ reached $\sim 0$, the solution was passed over a $1 \mathrm{~mL}$ Histrap HP column equilibrated with $25 \mathrm{mM} \mathrm{NH}_{4} \mathrm{HCO}_{3} \mathrm{pH} 8.5$ to remove MR. Subsequently, 200 U yeast alcohol dehydrogenase and $100 \mathrm{U}$ Aldehyde dehydrogenase as well as $0.5 \mathrm{ml}$ of $\left[{ }^{2} \mathrm{H} 6\right]$-ethanol were added and the $\mathrm{pH}$ of the buffered solution was adjusted to $\mathrm{pH} 8.5$ using liquid ammonia. (R,S)-[4- $\left.{ }^{2} \mathrm{H}_{2}\right]-\mathrm{NADH}$ was purified by anion exchange chromatography as described previously. ${ }^{26}$

All stopped-flow experiments were performed in $50 \mathrm{mM}$ potassium phosphate, $\mathrm{pH} 7.0$ using a Hi-Tech Scientific (TgK Scientific, Bradford on Avon, U.K.) stopped-flow spectrophotometer housed within an anaerobic glovebox (Belle Technology; $<5$ ppm $\mathrm{O}_{2}$ ). Spectral changes accompanying FMN reduction were monitored by absorption at $464 \mathrm{~nm}$. Typically, 5 measurements were taken for each reaction condition and transients were fitted using a double-exponential function, with $k_{\mathrm{obs}}$ taken to be the fastest phase, which also has the majority of the signal change/amplitude. Quoted rate constants are the average values \pm 1 standard deviation.

Computational. The main approximation to describe reaction kinetics in a chemical reaction, including those catalyzed by enzymes, is the Transition State Theory (TST), ${ }^{27-}$ ${ }^{29}$ which assumes that the selected reaction coordinate $(\xi)$ is separable from the rest of the system coordinates. Then, the reaction rate constant can be obtained from the difference between free energy in the TS and the reactants $\left(\Delta G^{\ddagger}\right)$. In a unimolecular process this rate constant is expressed as: 


$$
k_{r}(\xi, T)=\frac{k_{B} T}{h} \exp \left(-\frac{\Delta G^{\ddagger}(\xi)}{R T}\right)
$$

Nevertheless, if specific (protein) motions are coupled to the reaction coordinate, an explicit treatment for protein dynamical effects are required. TST offers a way to incorporate non-statistical effects by the calculation of a transmission coefficient $(\Gamma)$ that includes non-equilibrium effects due to the reaction-protein coupling and quantum effects. ${ }^{29,30}$

The initial coordinates used for the computational simulations are based on the crystal structure of MR with FMN and 1,4,5,6-tetrahydro-NADH $\left(\mathrm{NADH}_{4}\right.$; PDB code 2R14) ${ }^{20}$ at $1.40 \AA$ resolution, where nonreactive $\mathrm{NADH}_{4}$ have been modified to NADH. The missing coordinates of residues such as W279 to I284 have been taken from another structure (PDB code $1 \mathrm{GWJ}){ }^{31}$ by overlaying both structures.

The protonation state of ionizable residues in the protein environment corresponding to pH 7 was obtained using the PropKa 3.1 program. ${ }^{32-34}$ Then, the coordinates of the hydrogen atoms were added using the fDYNAMO ${ }^{35}$ library. The whole system was solvated with a pre-equilibrated box of water molecules with dimensions $100 \times 80 \times 80$ $\AA^{3}$. To neutralize the charge of the system, 20 sodium ions were added. The final system contains a total of 63199 atoms, of which 61 (31 from NADH and 30 from FMN) were described in the quantum-mechanical (QM) region and the rest in the molecular-mechanical (MM) region. The quantum subsystem includes parts of the cofactor (nicotinamide ring and the ribose) and the substrate (isoalloxazine ring and the first $\mathrm{CH}_{2}$ ) in such way that the border between quantum and classical parts is done in a $\mathrm{C}-\mathrm{C}$ bond (see Scheme 2). Cutoff radii between 10 and $14 \AA$ were used for all types of interaction. All the calculations were done under periodic boundary conditions. ${ }^{36}$ The waters and the sodium ions were re-equilibrated by means of 100 ps of molecular dynamics simulation in the NVT ensemble at the reference temperature of $298 \mathrm{~K}$ using the Langevin integrator with a time step of 1 fs. After a conjugate gradient minimization, ${ }^{37}$ the whole system was gradually warmed up to $298 \mathrm{~K}$ during $200 \mathrm{ps}$ and further equilibrated at this temperature for an additional 500 ps. 5 ns of MM simulation for the reactant state rendered very similar structural parameters than the $Q M / M M$ simulation (see Supporting Information, Table S6). 


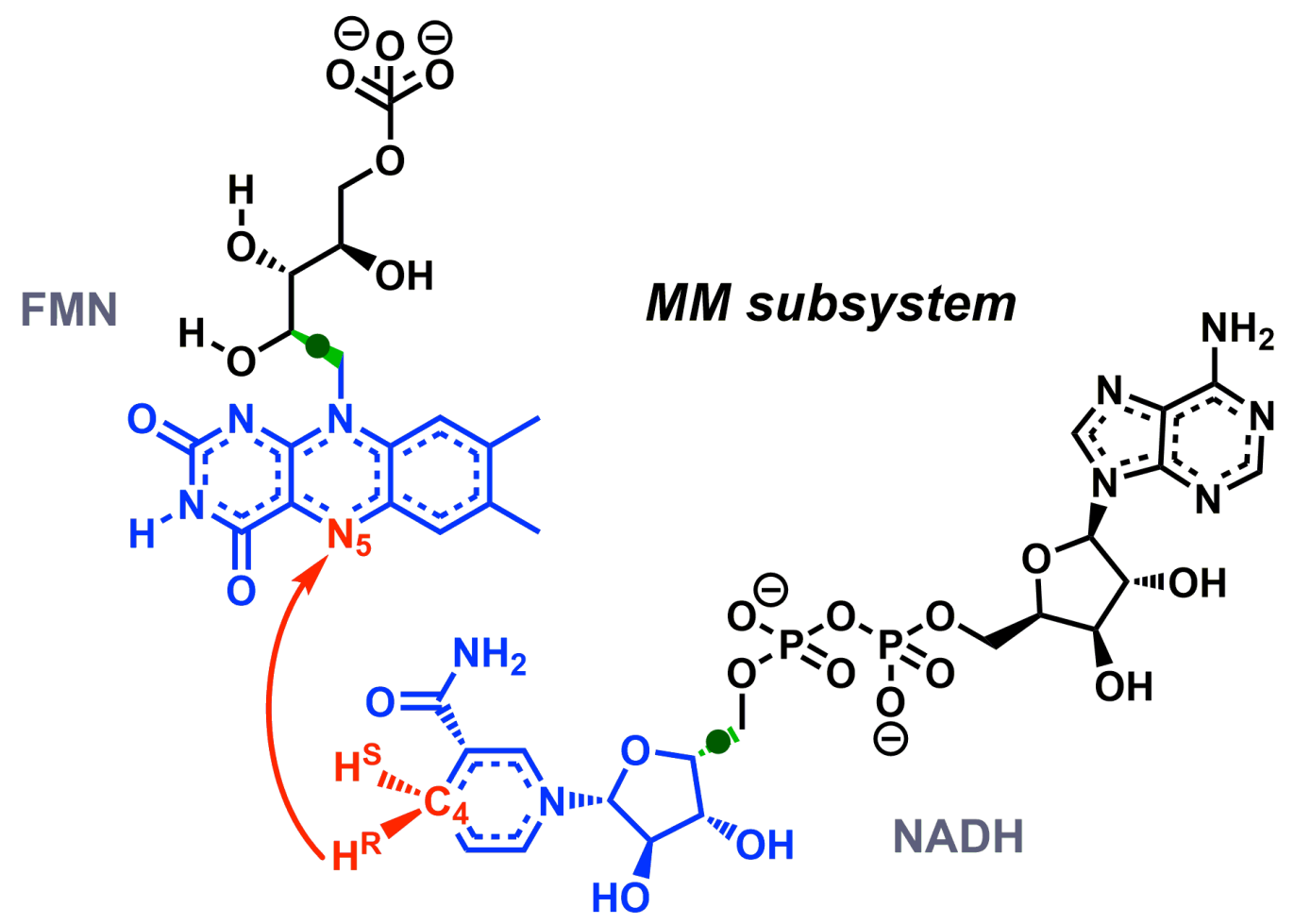

\section{QM subsystem}

Scheme 2. Representation of the active site of MR showing the QM/MM partitioning scheme. The QM part is colored in blue while MM part is colored in black. Green circles represent the quantum hydrogen link atoms. Key atoms in substrate/cofactor have been labeled in red.

The RM1 semiempirical method ${ }^{38}$ was selected to describe the QM region, after demonstarting its good performance for other enzyme catalyzed hydride transfer reactions. ${ }^{39,40}$ As shown in Table S5 in the Supporting Information, this method provides energy barriers and TS geometries for the hydride transfer in good agreement with B3LYPD-D3/6-31G(d,p) results. ${ }^{41}$ The MM region was described using the OPLS force field for the protein atoms, ${ }^{42}$ and the TIP3P model for water molecules. ${ }^{36}$ These methods are implemented in the fDYNAMO library. ${ }^{35}$

One-dimensional potentials of mean force (PMF) were generated in the NVT ensemble by using the antisymmetric combination of the distances describing the hydride transfer, that is, the breaking and forming bond, as the distinguished reaction coordinate $\xi$. These calculations were computed for the enzyme system using the umbrella sampling approach combined with the weighted histogram analysis method (WHAM). ${ }^{43,44}$ A total of 75 windows were needed to explore the reaction coordinate in a range from -2.60 to $1.84 \AA$. Each simulation consists of 10 ps of equilibration and 30 ps of production, 
employing a time step of 1 fs and a force constant of $2500 \mathrm{~kJ} \mathrm{~mol}^{-1} \AA^{-2}$ to keep the system restrained at the reference values of the reaction coordinate. The canonical ensemble NVT with the Langevin-Verlet algorithm was used to update the velocities at the reference temperature of $298 \mathrm{~K} .^{45,46}$

In order to correct the slight underestimated activation energies resulting from the lowlevel RM1 energy function used in the PMF calculations (see Table S5 in Supporting Information), an interpolated correction scheme developed in our group was applied. ${ }^{47}$ This scheme is based in a previous one developed by Truhlar and co-workers for dynamical calculations of gas phase chemical reactions. ${ }^{48}$ The new energy function, as a result of this correction, is defined as:

$$
E_{\text {corr }}=E^{L L}+S\left\lfloor\Delta E_{L L}^{H L}(\xi)\right\rfloor
$$

where $\mathrm{E}^{\mathrm{LL}}$ denotes the energy provided by the low-level method (LL) and $\mathrm{S}$ is a cubic spline function described by the correction term $\Delta E_{L L}^{H L}(\xi)$. This correction term comes from the difference between single-point calculations at higher theoretical levels (HL) and lower-level ones. In this case, the high-level method is B3LYPD-D3 with 6$31 \mathrm{G}(\mathrm{d}, \mathrm{p})$ basis set, $^{41}$ which has been extensively certified for hydride transfer reactions. $^{49}$ The low-level method is the semi-empirical RM1 Hamiltonian. This correction term is expressed as a function of the distinguished reaction coordinate $(\xi)$. The high-level method calculations were performed using Gaussian09. ${ }^{50}$

Deviations from canonical TST can be estimated by means of Ensemble-Averaged Variational TST (EA-VTST). ${ }^{51-53}$ The following expression is used to estimate the theoretical rate constant:

$$
k_{\text {theor }}(T)=\Gamma(T, \xi) \frac{k_{B} T}{h} \exp \left(-\frac{\Delta G_{a c t}^{Q C}(T, \xi)}{R T}\right)
$$

$\Delta G_{a c t}^{Q C}$ is the quasi-classical activation free energy at the TS, which is obtained from the classical mechanical (CM) PMF and including a correction for quantizing the vibrations orthogonal to the reaction coordinate ant the vibrational free energy of the reactant mode that correlates with motion along the reaction coordinate (see the Supporting Information for details). 
$\Gamma(T, \xi)$ is the temperature-dependent transmission coefficient which includes dynamic contributions to the classical rate. It can be expressed as:

$$
\Gamma(T, \xi)=\gamma(T, \xi) \cdot \kappa(T)
$$

where $\gamma(T, \xi)$ is the recrossing transmission coefficient and $\kappa(T)$ is the QMT coefficient. Grote-Hynes theory was been used to compute $\gamma(T, \xi)$ while $\kappa(T)$ was calculated with the microcanonical optimized multidimensional QMT ( $\mu \mathrm{OMT}$ ) approximation, which includes reaction-path curvature appropriate for enzymatic hydride transfers. ${ }^{29,30}$ The final QMT contribution is obtained as the average over the reaction paths of $25 \mathrm{TS}$ structures. In order to obtain these structures, a $125 \mathrm{ps} \mathrm{QM} / \mathrm{MM}$ dynamic was performed at the TS constrained reaction coordinate. Every structure was taken from 5 ps separated snapshots.

An effective activation free energy can then be described as the theoretical free energy barrier after the inclusion of dynamic contributions:

$$
k_{\text {theor }}(T)=\Gamma(T, \xi) \frac{k_{B} T}{h} \exp \left(-\frac{\Delta G_{a c t}^{Q C}(T, \xi)}{R T}\right)=\frac{k_{B} T}{h} \exp \left(-\frac{\Delta G_{\text {eff }}(T)}{R T}\right)
$$

Finally, the KIEs are calculated as the quotient between $\mathrm{HH}$ isotopologue rate constant and the rest of isotopologue rate constants, such $k^{\mathrm{HH}} / k^{\mathrm{DH}}$ is the primary $\mathrm{KIE}, k^{\mathrm{HH}} / k^{\mathrm{HD}}$ is the alpha-secondary KIE and $k^{\mathrm{HH}} / k^{\mathrm{DD}}$ is the 'double' KIE.

\section{Results and Discussion}

Reaction free energy profile. The free energy profile for the hydride transfer obtained in terms of a 1D-PMF is shown in Figure 1. As mentioned in the Computational Methodology section, the reaction coordinate is described as the difference between the breaking and forming bond distances:

$$
\xi=d(C-H)-d(N-H)
$$

While a more complete reaction coordinate could be defined including some other substrate and protein motions apart from the hydride stretch, the antisymmetric reaction 
coordinate employed in this study has been commonly used in previous proton and hydride transfers analysis and allows an analysis of dynamic and quantum effects on the reaction and on the KIEs, once the prefactor in eq. (5) is considered. ${ }^{4,51-54}$ The activation free energy that can be deduced from the difference between the maximum of the PMF and the reactant state $(\mathrm{RS})$ is $19.0 \mathrm{kcal} \mathrm{mol}^{-1}$. The hydride transfer reaction is endergonic, with the product state (PS) $10.1 \mathrm{kcal} \mathrm{mol}^{-1}$ above the RS. This arises due to significant charge separation during the hydride transfer reaction, with the reduced FMN negatively charged and the oxidized $\mathrm{NAD}^{+}$positively charged. The reaction is not $\mathrm{pH}$ dependent, ${ }^{18}$ which suggests that protonation of the reduced FMN occurs in a subsequent step to hydride transfer. Charge neutralization likely occurs by $\mathrm{NAD}^{+}$ dissociation, which is not considered in the present work.

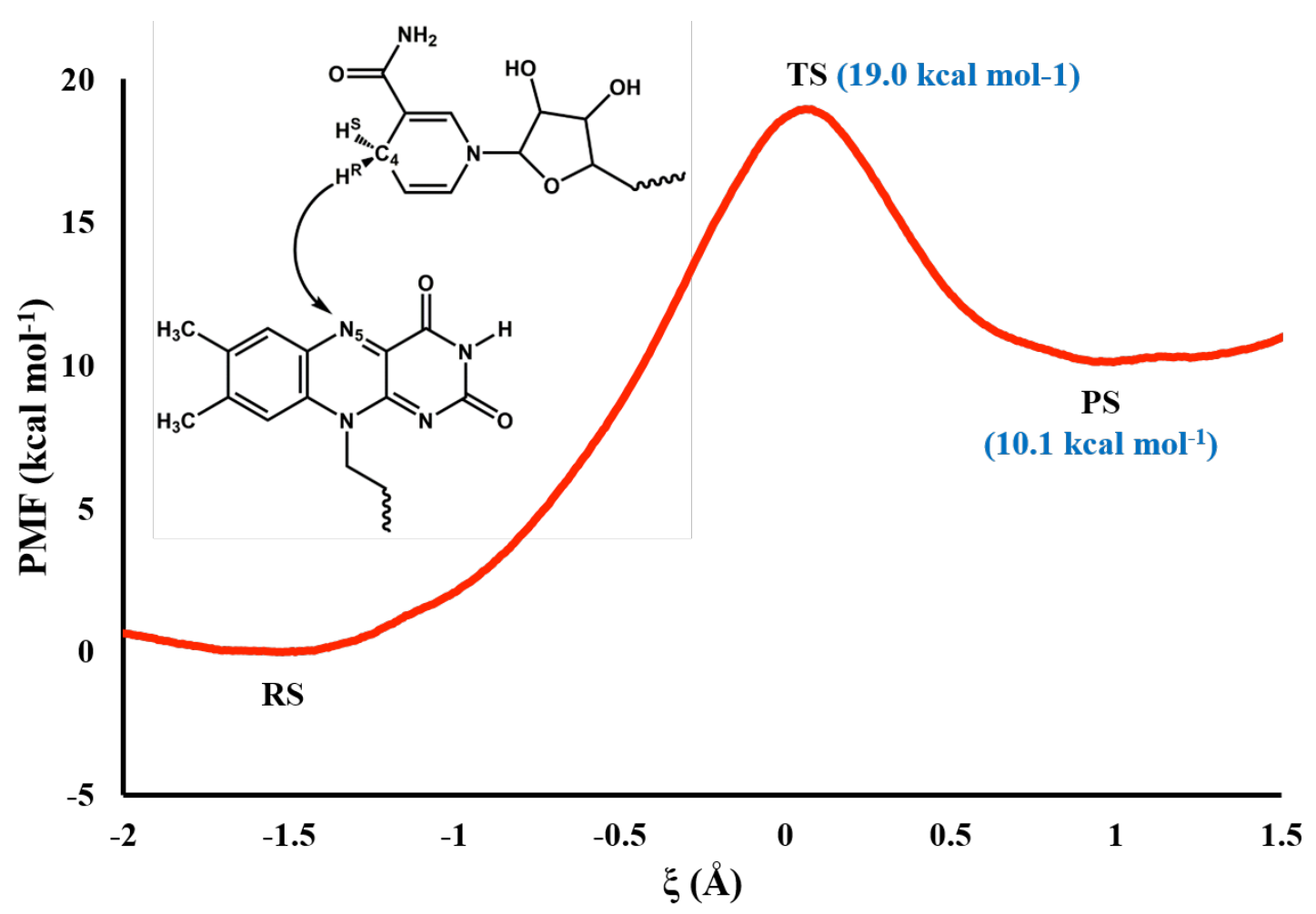

Figure 1. Classical mechanical B3LYP-D3:RM1/MM Potential of Mean Force (PMF) of hydride transfer catalyzed by MR at $298 \mathrm{~K}$.

Structural analysis. The average key distances of the three states involved in the reaction (RS, TS and PS) are listed in Table 1. The distance between donor (NADH C4) and acceptor (FMN N5) decreases from $3.65 \pm 0.10 \AA$ in the RS to $2.47 \pm 0.07 \AA$ in the 
TS, and then increases to $2.97 \pm 0.07$ in the product state (PS; see Figure 2). The transferred hydride $\left(\mathrm{H}^{\mathrm{R}}\right) \mathrm{C} 4-\mathrm{H}^{\mathrm{R}}$ and $\mathrm{N} 5-\mathrm{H}^{\mathrm{R}}$ bond lengths are $1.11 \pm 0.04 \AA$ and $1.03 \pm$ $0.03 \AA$ in the RS and PS configurations, respectively while it appears that hydride transfer occurs when the $\mathrm{C} 4-\mathrm{H}^{\mathrm{R}}-\mathrm{N} 5$ angle approaches linearity; the $\mathrm{C} 4-\mathrm{H}^{\mathrm{R}}-\mathrm{N} 5$ angle increases from $(147 \pm 12)^{\circ}$ in the RS to $(161 \pm 8)^{\circ}$ in the TS and then remains largely unchanged into the PS. Stacking of the NADH nicotinamide and oxidized FMN isoalloxazine rings results in a charge transfer complex, with significant $\pi$ orbital overlap. This stacking can be monitored between those atoms para to the $\mathrm{H}^{\mathrm{R}}$ donor and acceptor, i.e. the FMN N10 to NADH N1 distance (Figure 2). This distance decreases from $4.6 \pm 0.3 \AA$ in the RS to $4.03 \pm 0.24 \AA$ in the TS, where it then remains largely unchanged into the PS. Likewise, the distance between the centroids (Ø) of the nicotinamide and central isoalloxazine rings follows the same trend decreasing from $4.19 \pm 0.17 \AA$ in the RS to $3.39 \pm 0.13 \AA$ in the TS, before increasing slightly to $3.64 \pm$ $0.12 \AA$ in the PS. Consequently, these parameters collectively show that the rings of the FMN isoalloxazine and NADH nicotinamide moieties remain stacked roughly parallel to each other along the whole reaction process. This is in contrast to the results of a previous work, ${ }^{19}$ which is discussed below.

In order to analyze the interactions between the protein and substrate-cofactor complex, all the key distances are reported in Scheme S1 and Table S8 in the Supporting Information. From all of these distances, the most important are those directly related with the charge transfer associated to the reaction step. NADH becomes positively charged after the hydride transfer and, consequently, the H-bond from ASN189 to O7N should become weaker and longer as the reaction proceeds. Observing Table 1, one could see that this distance increases from $3.00 \pm 0.19$ to $3.18 \pm 0.24 \AA$ A. Additionally, FMN becomes negatively charged and the H-bond from ARG238 to N1 should be stronger, which is revealed by a shorter distance. This distance decreases from $2.98 \pm$ 0.10 to $2.95 \pm 0.10 \AA$. The trends are the expected ones, but the observed changes in distances are small and within the standard deviations associated to the thermal fluctuations in each of the states. This observation suggests that the active site is wellprepared to accommodate this charge transfer reaction or, in other words, that the active site is almost perfectly preorganized for the reaction. This conclusion can be supported by computing a more global property such as the evolution of the electrostatic potential created by the protein on the donor and acceptor atoms. The difference between these 
two values gives an estimation of the environmental effect on the charge transfer associated to the hydride transfer. This difference has been computed to be $138 \pm 23$ $\mathrm{kJ} \cdot \mathrm{mol}^{-1} \cdot \mathrm{e}^{-1}$ at the reactant state and $150 \pm 20 \mathrm{~kJ} \cdot \mathrm{mol}^{-1} \cdot \mathrm{e}^{-1}$ at the TS. The small change of the electrostatic potential from reactants state to the TS is in agreement with a small reorganization of the protein during the hydride transfer, as deduced from the structural analysis. In contrast, there are significant changes on other substrate coordinates that seem to be more strongly coupled to the reaction advance. For example, hybridization coordinates of the donor and acceptor atoms change substantially from the reactant state to the product state. One example is the evolution of the improper dihedral angle of the secondary $\mathrm{H}\left(\mathrm{H}^{\mathrm{S}}\right)$ atom on the donor atom $(\mathrm{C} 4)$. This motion takes place in a similar time scale than the hydride transfer. The corresponding frequencies at the TS are $1414 \mathrm{i}$ and $1495 \mathrm{i} \mathrm{cm}^{-1}$ for the improper dihedral angle and the hydride transfer, respectively, as determined from inspection of the normal modes derived from the hessian calculated for the QM region. 
Table 1. Key Parameters of the RS, TS and PS. All distances and their standard deviations (reported in $\AA$ ) and angles (reported in degrees) were obtained from 100 ps $\mathrm{QM} / \mathrm{MM}$ MD simulations on each state.

\begin{tabular}{|c|c|c|c|}
\hline & RS & TS & PS \\
\hline$d\left(\mathrm{C4}_{\mathrm{NADH}}-\mathrm{H}_{\mathrm{t}}\right)-d\left(\mathrm{N5}_{\mathrm{FMN}}-\mathrm{H}^{\mathrm{R}}\right)$ & $-1.56 \pm 0.04$ & $0.06 \pm 0.04$ & $0.96 \pm 0.03$ \\
\hline$\alpha\left(C 4_{\text {NADH }}-H^{R}-\mathbf{N 5}_{\text {FMN }}\right)$ & $147 \pm 12$ & $161 \pm 8$ & $162 \pm 8$ \\
\hline$d\left(\mathrm{C} 4_{\mathrm{NADH}}-\mathrm{N} 5_{\mathrm{FMN}}\right)$ & $3.65 \pm 0.10$ & $2.45 \pm 0.07$ & $2.97 \pm 0.07$ \\
\hline$d\left(C 4_{\mathrm{NADH}}-\mathbf{H}^{\mathrm{R}}\right)$ & $1.11 \pm 0.04$ & $1.27 \pm 0.04$ & $1.98 \pm 0.04$ \\
\hline$d\left(\mathbf{N} 5_{F M N}-\mathbf{H}^{\mathrm{R}}\right)$ & $2.67 \pm 0.05$ & $1.22 \pm 0.04$ & $1.03 \pm 0.03$ \\
\hline$d\left(\varnothing_{\text {nicotinamide }}-\emptyset_{\text {isoalloxazine }}\right)$ & $4.19 \pm 0.17$ & $3.39 \pm 0.13$ & $3.64 \pm 0.12$ \\
\hline$d\left(\mathrm{N1}_{\mathrm{NADH}}-\mathrm{N} 10_{\mathrm{FMN}}\right)$ & $4.6 \pm 0.3$ & $4.03 \pm 0.24$ & $4.04 \pm 0.21$ \\
\hline$d\left(\mathbf{O 7 N}_{\mathrm{NADH}}-\mathrm{ND2} 2_{\mathrm{ASN} 189}\right)$ & $3.00 \pm 0.19$ & $3.11 \pm 0.24$ & $3.18 \pm 0.24$ \\
\hline$d\left(\mathrm{N1}_{\mathrm{FMN}}-\mathrm{N} 10\right.$ ARG238 $)$ & $2.98 \pm 0.10$ & $2.96 \pm 0.10$ & $2.95 \pm 0.10$ \\
\hline $\begin{array}{l}\text { Improper dihedral } \\
\left(\mathrm{C5}-\mathrm{C} 3-\mathrm{C} 4-\mathrm{H}^{\mathrm{S}}\right)_{\mathrm{NADH}}\end{array}$ & $125 \pm 5$ & $138 \pm 6$ & $172 \pm 6$ \\
\hline
\end{tabular}
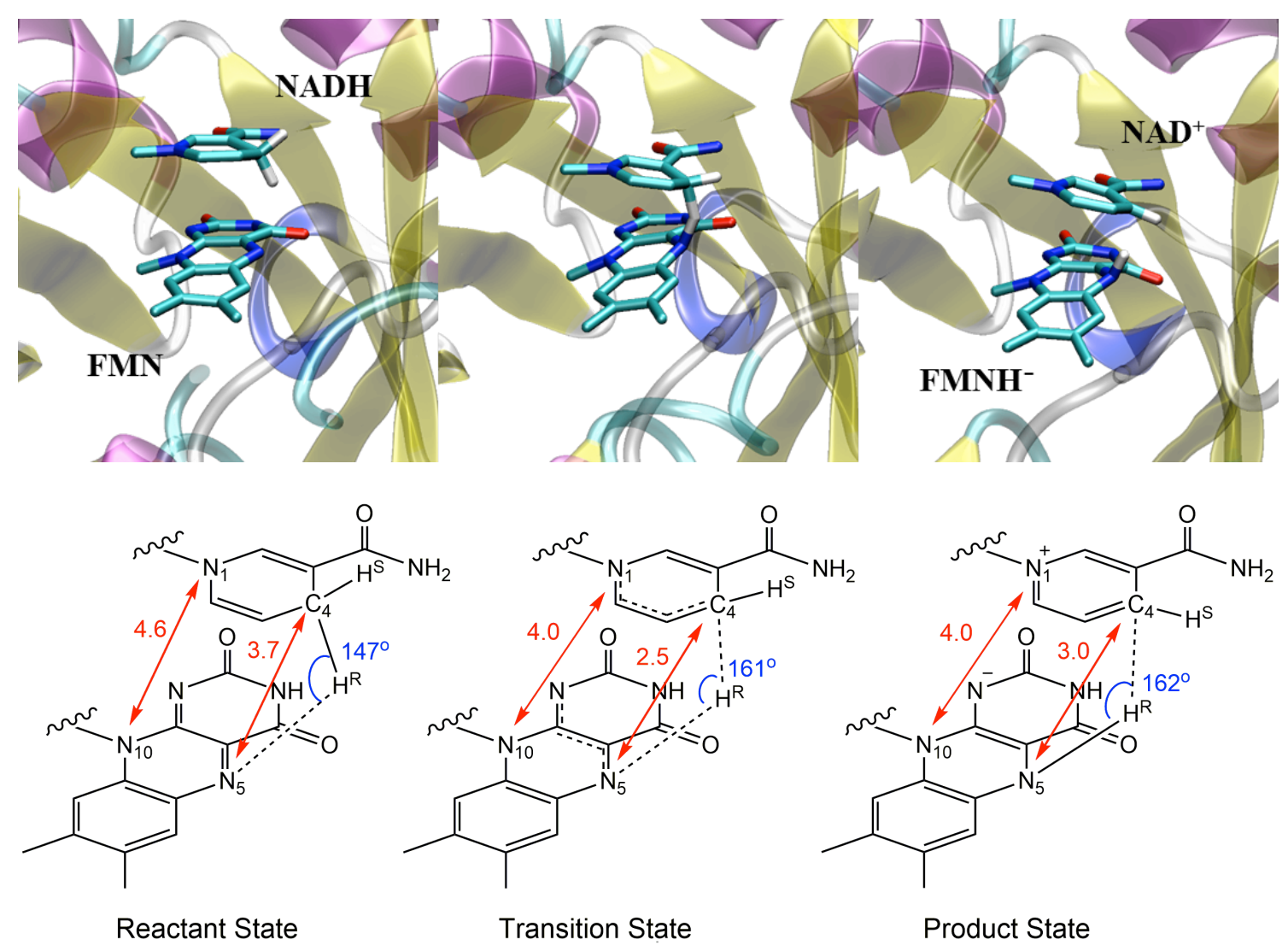

Figure 2. Top, Representative snapshots of the active site of MR in the RS, TS and PS configurations. For clarity, only the isoalloxazine moiety of FMN and nicotinamide moiety of NADH are shown. Below, a schematic of each configuration showing key distances (red in $\AA$ ) and angles (blue). 
Rate constants. The rate of hydride transfer has been experimentally measured for all four NADH isotopologues, essentially as described previously ${ }^{20,21}$ by monitoring the absorbance change at $464 \mathrm{~nm}$ associated with FMN reduction (concomitant with hydride transfer) during an anaerobic stopped-flow experiment. The concentration dependence of the reaction of MR with each NADH isotopologue is shown in Figure 3, with the limiting rate constants given in Table 2. Care was taken to prepare isotopologues with maximal isotopic purity (Figure S1), but unfortunately deuterium incorporation at the $\mathrm{H}^{\mathrm{S}}$ position of the DD $\left(\left[4-\mathrm{H}_{2}\right]-\mathrm{NADH}\right)$ coenzyme was not complete. Consequently, a linear extrapolation method was used to correct the limiting rate constant (Figure S2).

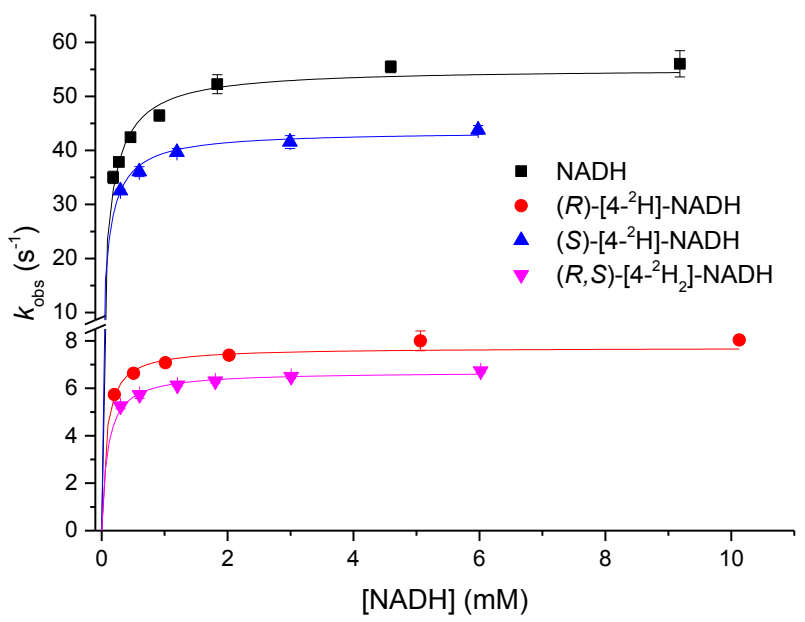

Figure 3. Coenzyme concentration dependence of the reaction of $20 \mu \mathrm{M}$ MR with each $\mathrm{NADH}$ isotopologue at $298 \mathrm{~K}$ in $50 \mathrm{mM}$ potassium phosphate, $\mathrm{pH} 7.0$ under anaerobic conditions. Data are fitted to: $k_{\mathrm{obs}}=k_{\lim }[\mathrm{NADH}] /\left(K_{\mathrm{S}}+[\mathrm{NADH}]\right)$, with fitting parameters given in Table S1.

Quasi-classical activation free energy $\left(\Delta G_{a c t}^{Q C}\right)$ and the final theoretical estimation of the phenomenological free energy of activation $\left(\Delta G_{\text {eff }}\right)$ are listed in Table 2. $\Delta G_{\text {act }}^{Q C}$ includes the quantal correction corresponding to the reaction coordinate and the vibrational modes orthogonal to it. As expected, the introduction of the quantal corrections reduces the free energy barriers in a value of 2.6, 1.9, 2.5 and $1.8 \mathrm{kcal} \mathrm{mol}^{-1}$ for $\mathrm{HH}, \mathrm{DH}, \mathrm{HD}$ and DD isotopic substitutions, respectively. As a result, the free energy of activation at $298 \mathrm{~K}$ decreases from $19.0 \mathrm{kcal} \mathrm{mol}^{-1}$ of the classical PMF to 16.4, 17.1, 16.5, $17.2 \mathrm{kcal} \mathrm{mol}^{-1}$ for the quasi-classical PMF for HH, DH, HD and DD 
reactions, respectively. The magnitude of these corrections is dominated by the isotope in the first position and can be compared with previous studies on hydride transfer

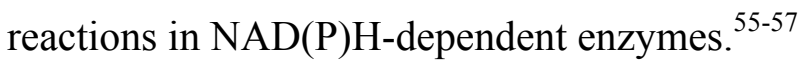

According to eq. (5) the EA-VTST rate constant also depends on the recrossing $(\gamma)$ and tunneling $(\kappa)$ coefficients. The first term determines the coupling between the reaction coordinate and other motions within the protein-FMN-NADH complex (the bath) and is obtained by means of application of Grote-Hynes theory, ${ }^{58}$ as detailed in the Computational Methodology section. These $\gamma$ values are listed in Table 2, and are almost invariant between the reactions of the four NADH isotopologues. It is important to note that, as stated in eq. (4), the value of $\gamma$ is dependent on the selected reaction coordinate. $^{53}$ Therefore, the obtained values, significantly different from unity, indicates that the simple distinguished reaction coordinate used in this study, eq. (6), does not correspond to the complete "real" reaction coordinate, which may involve other internal coordinates (substrate or protein motions) coupled to the hydride transfer itself. As mentioned before, hydride transfer is coupled to hybridization change on several atoms within the NADH and FMN and a more complete definition of the reaction coordinate should also consider, at least, these changes. Such a reaction coordinate would result in a better definition of the TS and a larger value in the recrossing coefficient. From the structural analysis presented above, it seems that substrate coordinates would play a more influential role than protein coordinates in the search for a more complete reaction coordinate. In any case, the recrossing coefficients values obtained when using the antisymmetric combination of distances as reaction coordinate imply small changes in the apparent barrier in a range of $0.39-0.50 \mathrm{kcal} \mathrm{mol}^{-1}$ (obtained from $-R T \ln \gamma$ ). Consequently, the selected distinguished coordinate can be considered a good enough reaction coordinate, providing a reasonable description of the TS ensemble. 
Table 2. Transmission Coefficient Components Due to Recrossing $(\gamma)$ and Tunneling

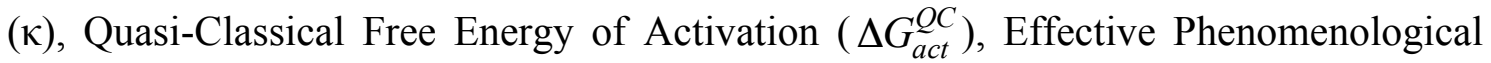
Free Energies of Activation ( $\Delta G_{\text {eff }}$ ), Theoretical Hydride Transfer Rate Constants $\left(k_{\text {theor }}\right)$, computed by means of eq. (5), and Experimental Hydride Transfer Rate Constants $\left(k_{\exp }\right)$ determined at $298 \mathrm{~K}$.

\begin{tabular}{ccccccc} 
& $\boldsymbol{\gamma}$ & $\boldsymbol{\kappa}$ & $\begin{array}{c}\Delta G_{a c t}^{Q C} \\
\left(\mathbf{k c a l ~ m o l}^{-\mathbf{1}}\right)\end{array}$ & $\begin{array}{c}\Delta G_{\text {eff }} \\
\left(\mathbf{k c a l ~ m o l}^{-\mathbf{1}}\right)\end{array}$ & $\begin{array}{c}\boldsymbol{k}_{\text {theor }} \\
\left(\mathbf{s}^{-1}\right)\end{array}$ & $\begin{array}{c}\boldsymbol{k}_{\text {exp }}^{\text {b }} \\
\left(\mathbf{s}^{-1}\right)\end{array}$ \\
HH & $0.48 \pm 0.01^{\mathrm{a}}$ & $23.8 \pm 5.5$ & $16.4 \pm 0.2$ & $15.0 \pm 0.3$ & $69 \pm 26$ & $55.8 \pm 1.1$ \\
DH & $0.52 \pm 0.01$ & $11.4 \pm 2.2$ & $17.1 \pm 0.1$ & $16.1 \pm 0.2$ & $11 \pm 3$ & $7.92 \pm 0.14$ \\
HD & $0.51 \pm 0.01$ & $17.4 \pm 3.9$ & $16.5 \pm 0.2$ & $15.2 \pm 0.3$ & $51 \pm 20$ & $43.6 \pm 1.7$ \\
DD & $0.43 \pm 0.01$ & $9.9 \pm 1.9$ & $17.2 \pm 0.1$ & $16.3 \pm 0.2$ & $7.2 \pm 2.3$ & $6.43 \pm 0.08$ \\
\hline
\end{tabular}

${ }^{a}$ Error in tunneling and vibrational corrections are the standard deviation determined from the 25 different structures. Error in the transmission coefficient is determined according to ref. $58 .{ }^{\mathrm{b}} k_{\exp }$ correspond to $k_{\lim }$ values given in Table $\mathrm{S} 1$.

The high values of the QMT coefficient, $\kappa=23.8 \pm 5.5$ for the reaction of the fully protiated NADH, calculated using the $\mu \mathrm{OMT}$ approximation, ${ }^{29,30}$ suggests that QMT can play an important role in the reaction. If the degree of QMT in the reaction is taken to be $100(1-1 / \kappa) \%$, then the reaction of the HH, DH, HD and DD NADH isotopologues is seen to proceed via $94-97 \%, 89-93 \%, 92-96 \%$ and $87-92 \%$ QMT, respectively. As expected, this trend is inversely proportional to the weight of the involved atoms, being higher with protium and lower with deuterium. In energetic terms, QMT lowers the effective free energy barrier by $\Delta \Delta G=-1.88,-1.44,-1.69$ and $-1.35 \mathrm{kcal} \mathrm{mol}^{-1}$ for reactions with the $\mathrm{HH}, \mathrm{DH}, \mathrm{HD}$ and $\mathrm{DD} \mathrm{NADH}$ isotopologues, respectively. The extent of barrier reduction due to QMT is similar to the predictions on previous theoretical studies for hydrogen transfer catalyzed by methylamine dehydrogenase $(-1.9 \mathrm{kcal}$ $\left.\mathrm{mol}^{-1}\right)^{59}$, dihydrofolate reductase $\left(-0.8 \mathrm{kcal} \mathrm{mol}^{-1}\right)^{30}$, thymidylate synthase $(-1.4 \mathrm{kcal}$ $\left.\mathrm{mol}^{-1}\right)^{10}$ or lactate dehydrogenase $\left(-0.8 \mathrm{kcal} \mathrm{mol}^{-1}\right)^{60}$, but notably smaller than those reported for methylamine dehydrogenase $\left(-3 \mathrm{kcal} \mathrm{mol}^{-1}\right)^{61}$, aromatic ammine dehydrogenase $\left(-4.9 \mathrm{kcal} \mathrm{mol}^{-1}\right)^{62}$ and soybean lipoxygenase-1 $\left(-3.6 \mathrm{kcal} \mathrm{mol}^{-1}\right) .^{63}$

Kinetic Isotope Effects. The experimental KIEs, deduced from the $k_{\lim }$ values given in Table 2, are provided in Table 3, together with the theoretical KIEs and the contribution of each factor (quantum vibrational correction, recrossing and QMT) to the final 
theoretical KIE. The largest contribution to the KIEs on deuterium transfer is the difference in quantum mechanical vibrational corrections $(Q C), 3.22 \pm 0.17$ and $3.52 \pm$ 0.19 for $1^{\circ}$ and double KIE, respectively, followed by QMT contribution $(\kappa), 2.1 \pm 0.3$ and $2.4 \pm 0.3$, for each case. Conversely, the largest contribution to the $2^{\circ} \mathrm{KIE}$ is the difference in QMT, which is $1.36 \pm 0.09$, followed by a similar contribution of quantum mechanical vibrational corrections and recrossing $(\gamma), 1.06 \pm 0.03$ and $0.94 \pm 0.04$, respectively.

The $K I E_{\text {theor }}$ values are in excellent agreement with the newly measured experimental values given in Table 3. Failure of the rule of the geometric mean (eq 7) is used as evidence for the role of QMT during $\mathrm{H}$ transfer reactions. ${ }^{21,64-66}$

$$
\text { Double } \mathrm{KIE}=1^{\circ} \mathrm{KIE} \times 2^{\circ} \mathrm{KIE}
$$

The theoretical and experimental KIEs determined in the present study (Table 3) allow a reassessment of this relationship and neither set of KIEs violates this principle.

Table 3. Experimental and KIEs calculated at $298 \mathrm{~K}$ and the contributions from quantum mechanical vibrational energy correction (QC), recrossing coefficient $(\gamma)$ and tunneling reflection coefficient $(\kappa)$

$\begin{array}{lccccc} & \boldsymbol{K I E}_{Q C} & \boldsymbol{K I E}_{\gamma} & \boldsymbol{K I E _ { \boldsymbol { \kappa } }} & \boldsymbol{K I E}_{\text {theor }} & \boldsymbol{K I E}_{\text {exp }} \\ \mathbf{1}^{\mathbf{0}} \mathbf{K I E} & 3.22 \pm 0.17 & 0.92 \pm 0.04 & 2.1 \pm 0.3 & 6.2 \pm 0.7 & 7.05 \pm 0.26 \\ \mathbf{2}^{\mathbf{0}} \mathbf{K I E} & 1.06 \pm 0.03 & 0.94 \pm 0.04 & 1.36 \pm 0.09 & 1.36 \pm 0.1 & 1.28 \pm 0.08 \\ \text { Double KIE } & 3.52 \pm 0.19 & 1.12 \pm 0.05 & 2.4 \pm 0.3 & 9.4 \pm 1.1 & 8.68 \pm 0.28 \\ \mathbf{1}^{\mathbf{0}} \times \mathbf{2}^{\mathbf{0}} \mathbf{K I E} & 3.41 \pm 0.28 & 0.86 \pm 0.07 & 2.9 \pm 0.6 & 8.4 \pm 1.6 & 9.02 \pm 0.90\end{array}$

Experimental KIEs were derived from the $k_{\exp }$ values given in Table 2.

As the $1^{\circ}$ and double KIEs are known to vary with temperature, ${ }^{21}$ the temperature dependence of the reactions with NADH and $(R)-\left[4{ }^{2} \mathrm{H}\right]-\mathrm{NADH}$ were also re-measured (Figure S3 in the Supporting Information). These data were fitted to a non-linear Eyring-based function, ${ }^{67,68}$ which we have recently used to analyze the temperature dependence of the hydride transfer catalyzed by the homologous enzyme PETNR. ${ }^{24}$ Of note is that the temperature dependence of the $1^{\circ} \mathrm{KIE}$ was confirmed to be quite large at 
$\Delta \Delta H^{\ddagger}=2.0 \pm 0.2 \mathrm{kcal} \mathrm{mol}^{-1}$ and $\Delta \Delta S^{\ddagger}=2.8 \pm 0.7 \mathrm{cal} \mathrm{mol}^{-1} \mathrm{~K}^{-1}$ (Table 4 and Table $\mathrm{S} 3$ in the Supporting Information).

The variation of the entropic contribution, $\Delta \Delta S_{\text {eff }}$, to the activation free energy can be related to the QMT contribution to the rate constant, neglecting differences in recrossing coefficient (see Table 2). Using the definition of the effective activation free energy, see eq. (5), and assuming that changes in the quasi-classical activation free energy upon labeling (i.e. zero-point energies) are included in the enthalpic component, the dependency of $\Delta \Delta S_{\text {eff }}$ on the QMT coefficient can be expressed in the following way:

$$
\Delta \Delta S_{e f f} \approx-R \ln \frac{\kappa_{D}}{\kappa_{H}}-R \frac{\partial \ln \left(\kappa_{D} / \kappa_{H}\right)}{\partial T}
$$

Our simulation indicates that, although $\kappa$ changes with temperature, $T$, the ratio $\kappa_{D} / \kappa_{H}$ is approximately $T$ independent (see Supporting Information, Table S9). Using $\kappa$ values in Table 2, we estimated $\Delta \Delta S_{\text {eff }}$ to be $1.4 \pm 0.3 \mathrm{cal} \mathrm{mol}^{-1} \mathrm{~K}^{-1}$. Moreover, based on the equation for the variation of the free energy in a constant pressure and constant temperature system, $\Delta \Delta H_{\text {eff }}$ can be expressed in the following manner:

$$
\Delta \Delta H_{e f f} \approx \Delta \Delta G_{e f f}+T \cdot \Delta \Delta S_{e f f}
$$

Using $\kappa$ and $\Delta \Delta G_{\text {eff }}$ values from Table 2, we estimated $\Delta \Delta H_{\text {eff }}$ to be $1.12 \pm 0.07 \mathrm{kcal}$ $\mathrm{mol}^{-1}$. Considering the inherent approximation in eq. (8) in the theoretical evaluation of the contributions to the rate constant, as well as the experimental uncertainties, the agreement between the estimated and observed $\Delta \Delta S_{\text {eff }}$ and $\Delta \Delta H_{\text {eff }}$ are reasonable and our simulations allow for an interpretation of these magnitudes. While the $\Delta \Delta H_{\text {eff }}$ is mainly due to the change in the impact of the ZPE on the energy barrier when $\mathrm{H}$ is substituted by $\mathrm{D}$, the effect on $\Delta \Delta S_{\text {eff }}$ is due to the reduction in QMT due to the increase in the mass of the transferred particle. These trends explain the sign of the observed change in the thermodynamic activation parameters, although a quantitative agreement is not reached. 
Table 4. Comparison between experimental and theoretical values for $\Delta \Delta H^{\ddagger}, \Delta \Delta S^{\ddagger}$ and $\Delta \Delta G^{\ddagger}$ at $298 \mathrm{~K}$.

\begin{tabular}{lccc} 
& $\begin{array}{c}\Delta \Delta H^{\ddagger} \\
\left(\mathrm{kcal} \mathrm{mol}^{-1}\right)\end{array}$ & $\begin{array}{c}\Delta \Delta S^{\ddagger} \\
\left(\mathrm{cal} \mathrm{mol}^{-1} \mathrm{~K}^{-1}\right)\end{array}$ & $\begin{array}{c}\Delta \Delta G^{\ddagger} \\
\left(\mathrm{kcal} \mathrm{mol}^{-1}\right)\end{array}$ \\
Experimental & $2.0 \pm 0.2$ & $2.8 \pm 0.7$ & $1.2 \pm 0.4$ \\
Theoretical & $1.12 \pm 0.07$ & $1.4 \pm 0.3$ & $0.69 \pm 0.03$ \\
\hline
\end{tabular}

Experimental values are taken from Table S3 in the Supporting Information, while theoretical values were obtained by using eqs. 8-9.

A comparison with previous work. A previous study of the QMT contribution to the MR-catalyzed hydride transfer reaction predicted a reduction in the free energy of activation of $\Delta \Delta G^{\ddagger}=-3.46 \mathrm{kcal} \mathrm{mol}^{-1}$ for the reaction of the $\mathrm{HH}$ isotopologue of NADH. ${ }^{19}$ A major difference between the previous study and this work is that in the present work the NADH nicotinamide and FMN isoalloxazine remain stacked in a parallel configuration along the entire reaction path, while this was not the case in the previous study, where the nicotinamide and isoalloxazine become almost perpendicular in the TS. It is expected to be energetically unfavorable to break the $\pi-\pi$ interactions involved in stacking of the isoalloxazine and nicotinamide rings, and we now show that this is not necessary to form a viable TS. As such, we suggest the perpendicular TS observed previously is likely an artifact arising from the employed QM method (the standard $\mathrm{AM} 1^{69}$ vs. the newer RM1 $1^{38}$ semiempirical method with DFT and dispersion corrections employed in the present study). The theoretical EA-VTST rate constants and KIEs in the current study (Tables 2 and 3 ) were obtained directly from computational calculations without any fitting with experimental data, so they provide a good measure of the accuracy of the computational methodology used. These values are in excellent agreement with experimental values (see Table 2). This agreement also differs from the previous study, where the calculated rate constants underestimated the experimental values by $5-10$-fold and the calculated $1^{\circ}$ KIE was overestimated by a factor of 2-3. ${ }^{19}$

An unusual feature of many of the primary KIEs on Old Yellow enzymes is their variable and often relatively high temperature dependence $\left(\Delta \Delta H^{\ddagger}\right){ }^{1}$ These KIEs have 
previously been interpreted as reporting on deep tunneling reactions assisted by protein (promoting) vibrations.e.g. ${ }^{17,21,24}$ It would be interesting in future work to further investigate the temperature dependence of the KIE by computing the different contributions to the rate constant (eq. (5)) at a range of temperatures. A dissection of the temperature dependence of each of these contributing terms could highlight the possible role of protein motions in the chemical step and its proper description within the current theoretical framework.

\section{Conclusions}

The present study combines computational and experimental methods to explore the basis of enzyme catalysis and quantify the importance of QMT during the reductive half reaction of MR with four NADH isotopologues. The excellent agreement between the experimental rate constants and KIEs and those predicted from calculations (see Tables 2 and 3) demonstrates that TST with QMT and recrossing corrections can accurately describe these reactions, even when the TS ensemble is defined in terms of a simple reaction coordinate, such as the antisymmetric stretch (eq. 6) used in this work. The largest contribution to the $1^{\circ}$ and double KIEs comes from the differences in quantum mechanical vibrational corrections, while the difference in QMT is responsible for the largest contribution to the computed $2^{\circ}$ KIEs. Differences in the recrossing coefficients are almost negligible between $\mathrm{H}$ and $\mathrm{D}$, either at the primary or secondary position. Analysis of key distances/angles in the active site along the stationary points show the FMN isoalloxazine and NADH nicotinamide moieties remain stacked parallel to each other along the entire reaction path. Thus, the enzyme ternary complex is well preorganized to carry out hydride transfer. According to the comparative analysis of the average structures on the reactant state and the TS, the evolution of a more global property such as the electrostatic potential created by the enzyme on the donor and acceptor atoms, or the obtained values of the recrossing transmission coefficient, largescale protein dynamics do not appear to be important and it appears that any functional dynamics can be described as an equilibrium fluctuation around the stationary points. Nevertheless, it would be interesting in future work to confirm this conclusion by further investigate the temperature dependence of the KIE, a behavior usually associated with 'promoting vibrations' playing a significant role in the chemical reaction step. 
While QMT does not appear to be as important as previously thought, ${ }^{19}$ it does play a significant role in the reductive hydride transfer by reducing the effective free energy of activation by 1-2 $\mathrm{kcal} \mathrm{mol}^{-1}$, leading to a 10-24 fold rate enhancement, depending on $\mathrm{NADH}$ isotopologue. The present study, which combines computational and experimental studies with an excellent agreement between theory and measurement, shows that MR (and by extension Old Yellow enzyme homologues of MR) is an excellent system to analyse the contribution of dynamics and tunnelling to catalysis.

\section{Supporting information}

Experimental limiting rate constants, apparent saturation constants and KIEs; isotopic purities; additional fitting parameters and kinetic analysis; additional information about computational methods; energy barriers and stationary points key distances by using different computational methods; additional key averaged parameters from MD simulations; complete QMT coefficient data; and QMT coefficient data at 278, 298 and $313 \mathrm{~K}$.

\section{Correspondig authors}

*S.H., e-mail, sam.hay@manchester.ac.uk

*V.M, e-mail, moliner@uji.es

*I.T., e-mail, ignacio.tunon@uv.es

\section{Acknowledgements}

This work was supported by the Spanish Ministerio de Economía y Competitividad (project CTQ2015-66223-C2), Universitat Jaume I (project P1·1B2014-26), Generalitat Valenciana (PROMETEOII/2014/022), UK Biotechnology and Biological Sciences Research Council (BBSRC; BB/M007065/1 and BB/ H021523/1), and N.S.S is an Engineering and Physical Sciences Research Council (EPSRC) Established Career 
Research Fellow (EP/J020192/1). V.M. is grateful to the University of Bath for the award of a David Parkin Visiting Professorship. The authors thankfully acknowledge the computer resources, technical expertise and assistance provided by the "Centre de Càlcul de la Universitat de València" through the use of Multivac and Tirant.

\section{References}

(1) Hay, S.; Scrutton, N. S. Nat. Chem. 2012, 4, 161.

(2) Glowacki, D. R.; Harvey, J. N.; Mulholland, A. J. Nat. Chem. 2012, 4, 169.

(3) Nagel, Z. D.; Klinman, J. P. Nat. Chem. Biol. 2009, 5, 543.

(4) Luk, L. Y. P.; Javier Ruiz-Pernía, J.; Dawson, W. M.; Roca, M.; Loveridge, E. J.; Glowacki, D. R.; Harvey, J. N.; Mulholland, A. J.; Tuñón, I.; Moliner, V.; Allemann, R. K. Proc. Natl. Acad. Sci. 2013, 110, 16344.

(5) Limbach, H.-H.; Schowen, K. B.; Schowen, R. L. J. Phys. Org. Chem. 2010, 23, 586.

(6) Loveridge, E. J.; Behiry, E. M.; Guo, J.; Allemann, R. K. Nat. Chem. 2012, 4, 292.

(7) Adamczyk, A. J.; Cao, J.; Kamerlin, S. C. L.; Warshel, A. Proc. Natl. Acad. Sci. 2011, 108, 14115.

(8) Gao, J.; Ma, S.; Major, D. T.; Nam, K.; Pu, J.; Truhlar, D. G. Chem. Rev. 2006, 106,3188

(9) Roca, M.; Moliner, V.; Tuñón, I.; Hynes, J. T. J. Am. Chem. Soc. 2006, 128, 6186.

(10) Kanaan, N.; Ferrer, S.; Martí, S.; Garcia-Viloca, M.; Kohen, A.; Moliner, V. J. Am. Chem. Soc. 2011, 133, 6692.

(11) Garcia-Viloca, M.; Gao, J.; Karplus, M.; Truhlar, D. G. Science 2004, 303, 186.

(12) Olsson, M. H. M.; Søndergaard, C. R.; Rostkowski, M.; Jensen, J. H. J. Chem. Theory Comput. 2011, 7, 525.

(13) Ruiz-Pernía, J. J.; Tuñón, I.; Moliner, V.; Hynes, J. T.; Roca, M. J. Am. Chem. Soc. 2008, 130, 7477.

(14) Klinman, J. P.; Kohen, A. Annu. Rev. Biochem. 2013, 82, 471.

(15) Tuñón, I.; Laage, D.; Hynes, J. T. Arch. Biochem. Biophys. 2015, 582, 42.

(16) Masterson, J. E.; Schwartz, S. D. J. Phys. Chem. B 2015, 119, 989.

(17) Hay, S.; Pudney, C. R.; McGrory, T. A.; Pang, J.; Sutcliffe, M. J.; Scrutton, N. S. Angew. Chem. Int. Ed. 2009, 48, 1452.

(18) Hay, S.; Pudney, C. R.; Sutcliffe, M. J.; Scrutton, N. S. ChemPhysChem 2008, 9, 1875.

(19) Pang, J.; Hay, S.; Scrutton, N. S.; Sutcliffe, M. J. J. Am. Chem. Soc. 2008, 130, 7092.

(20) Pudney, C. R.; Hay, S.; Pang, J.; Costello, C.; Leys, D.; Sutcliffe, M. J.; Scrutton, N. S. J. Am. Chem. Soc. 2007, 129, 13949.

(21) Pudney, C. R.; Hay, S.; Sutcliffe, M. J.; Scrutton, N. S. J. Am. Chem. Soc. 2006, $128,14053$.

(22) Basran, J.; Harris, R. J.; Sutcliffe, M. J.; Scrutton, N. S. J. Biol. Chem. 2003, 278, 43973.

(23) Craig, D. H.; Moody, P. C. E.; Bruce, N. C.; Scrutton, N. S. Biochemistry 1998, 37, 7598.

(24) Geddes, A.; Paul, C. E.; Hay, S.; Hollmann, F.; Scrutton, N. S. J. Am. Chem. Soc. 2016, 138, 11089.

(25) Hay, S.; Pudney, C. R.; Hothi, P.; Scrutton, N. S. J. Phys. Chem. A 2008, 112, 13109. 
(26) Pudney, C. R.; Hay, S.; Scrutton, N. S. In Flavins and Flavoproteins: Methods and Protocols; Weber, S., Ed.; Springer New York: New York, NY, 2014, p 161.

(27) Pauling, L. Chem. Eng. News 1946, 24, 1375.

(28) Warshel, A. Proc. Natl. Acad. Sci. 1978, 75, 5250.

(29) Pu, J.; Gao, J.; Truhlar, D. G. Chem. Rev. 2006, 106, 3140.

(30) Pang, J.; Pu, J.; Gao, J.; Truhlar, D. G.; Allemann, R. K. J. Am. Chem. Soc. 2006, 128, 8015.

(31) Barna, T.; Messiha, H. L.; Petosa, C.; Bruce, N. C.; Scrutton, N. S.; Moody, P. C. E. J. Biol. Chem. 2002, 277, 30976.

(32) Li, H.; Robertson, A. D.; Jensen, J. H. Proteins: Struct., Funct., Bioinf. 2005, 61, 704.

(33) Bas, D. C.; Rogers, D. M.; Jensen, J. H. Proteins: Struct., Funct., Bioinf. 2008, 73,

765.

(34) Søndergaard, C. R.; Olsson, M. H. M.; Rostkowski, M.; Jensen, J. H. J. Chem. Theory Comput. 2011, 7, 2284.

(35) Field, M. J.; Albe, M.; Bret, C.; Proust-De Martin, F.; Thomas, A. J. Comput. Chem. 2000, 21, 1088.

(36) Jorgensen, W. L.; Chandrasekhar, J.; Madura, J. D.; Impey, R. W.; Klein, M. L. J. Chem. Phys. 1983, 79, 926.

(37) Byrd, R. H.; Lu, P.; Nocedal, J.; Zhu, C. SIAM J. Sci. Comput. 1995, 16, 1190.

(38) Rocha, G. B.; Freire, R. O.; Simas, A. M.; Stewart, J. J. P. J. Comput. Chem. 2006, 27, 1101.

(39) Świderek, K.; Tuñón, I.; Martí, S.; Moliner, V. ACS Catalysis 2015, 5, 1172.

(40) Świderek, K.; Arafet, K.; Kohen, A.; Moliner, V. J. Chem. Theory Comput. 2017.

(41) Hehre, W. J.; Radom, L.; von R. Schleyer, P.; Pople, J. A. Ab Initio Molecular Orbital Theory; John Wiley \& Sons: New York, 1986.

(42) Jorgensen, W. L.; Maxwell, D. S.; Tirado-Rives, J. J. Am. Chem. Soc. 1996, 118, 11225.

(43) Torrie, G. M.; Valleau, J. P. J. Comput. Phys. 1977, 23, 187.

(44) Kumar, S.; Rosenberg, J. M.; Bouzida, D.; Swendsen, R. H.; Kollman, P. A. J. Comput. Chem. 1992, 13, 1011.

(45) Verlet, L. Physical Review 1967, 159, 98.

(46) Swope, W. C.; Andersen, H. C.; Berens, P. H.; Wilson, K. R. J. Chem. Phys. 1982, $76,637$.

(47) Ruiz-Pernía, J. J.; Silla, E.; Tuñón, I.; Martí, S.; Moliner, V. J. Phys. Chem. B 2004, $108,8427$.

(48) Chuang, Y.-Y.; Corchado, J. C.; Truhlar, D. G. J. Phys. Chem. A 1999, 103, 1140.

(49) Doron, D.; Major, D. T.; Kohen, A.; Thiel, W.; Wu, X. J. Chem. Theory Comput. 2011, 7, 3420.

(50) Frisch, M. J.; Trucks, G. W.; Schlegel, H. B.; Scuseria, G. E.; Robb, M. A.; Cheeseman, J. R.; Scalmani, G.; Barone, V.; Mennucci, B.; Petersson, G. A.; Nakatsuji, H.; Caricato, M. L., X.; Hratchian, H. P.; Izmaylov, A. F.; Bloino, J.; Zheng, G.; Sonnenberg, J. L.; Hada, M.; Ehara, M.; Toyota, K.; Fukuda, R.; Hasegawa, J.; Ishida, M.; Nakajima, T.; Honda, Y.; Kitao, O.; Nakai, H.; Vreven, T.; Montgomery, J. A., Jr.; Peralta, J. E.; Ogliaro, F.; Bearpark, M.; Heyd, J. J.; Brothers, E.; Kudin, K. N.; Staroverov, V. N.; Kobayashi, R.; Normand, J.;

Raghavachari, K.; Rendell, A.; Burant, J. C.; Iyengar, S. S.; Tomasi, J.; Cossi, M.; Rega, N.; Millam, J. M.; Klene, M.; Knox, J. E.; Cross, J. B.; Bakken, V.; Adamo, C.; Jaramillo, J.; Gomperts, R.; Stratmann, R. E.; Yazyev, O.; Austin, A. J.; Cammi, R.; Pomelli, C.; Ochterski, J. W.; Martin, R. L.; Morokuma, K.; Zakrzewski, V. G.; Voth, G. A.; Salvador, P.; Dannenberg, J. J.; Dapprich, S.; Daniels, A. D.; Farkas, Ö.; Foresman, J. B.; Ortiz, J. V.; Cioslowski, J.; Fox, D. J.; Gaussian, Inc.: Wallingford CT, 2009. 
(51) Alhambra, C.; Corchado, J.; Sánchez, M. L.; Garcia-Viloca, M.; Gao, J.; Truhlar, D. G. J. Phys. Chem. B 2001, 105, 11326.

(52) Truhlar, D. G.; Gao, J.; Alhambra, C.; Garcia-Viloca, M.; Corchado, J.; Sánchez, M. L.; Villà, J. Acc. Chem. Res. 2002, 35, 341.

(53) Truhlar, D. G.; Gao, J.; Garcia-Viloca, M.; Alhambra, C.; Corchado, J.; Luz Sanchez, M.; Poulsen, T. D. Int. J. Quantum Chem. 2004, 100, 1136.

(54) Luk, L. Y. P.; Ruiz-Pernía, J. J.; Dawson, W. M.; Loveridge, E. J.; Tuñón, I.; Moliner, V.; Allemann, R. K. J. Am. Chem. Soc. 2014, 136, 17317.

(55) Garcia-Viloca, M.; Alhambra, C.; Truhlar, D. G.; Gao, J. J. Chem. Phys. 2001, 114, 9953.

(56) Alhambra, C.; Corchado, J. C.; Sánchez, M. L.; Gao, J.; Truhlar, D. G. J. Am. Chem. Soc. 2000, 122, 8197.

(57) Webb, S. P.; Agarwal, P. K.; Hammes-Schiffer, S. J. Phys. Chem. B 2000, 104, 8884.

(58) Gertner, B. J.; Wilson, K. R.; Hynes, J. T. J. Chem. Phys. 1989, 90, 3537.

(59) Faulder, P. F.; Tresadern, G.; Chohan, K. K.; Scrutton, N. S.; Sutcliffe, M. J.; Hillier, I. H.; Burton, N. A. J. Am. Chem. Soc. 2001, 123, 8604.

(60) Ferrer, S.; Tuñón, I.; Martí, S.; Moliner, V.; Garcia-Viloca, M.; González-Lafont, À.; Lluch, J. M. J. Am. Chem. Soc. 2006, 128, 16851.

(61) Ranaghan , K. E.; Masgrau, L.; Scrutton, N. S.; Sutcliffe, M. J.; Mulholland, A. J. ChemPhysChem 2007, 8, 1816.

(62) Masgrau, L.; Roujeinikova, A.; Johannissen, L. O.; Hothi, P.; Basran, J.;

Ranaghan, K. E.; Mulholland, A. J.; Sutcliffe, M. J.; Scrutton, N. S.; Leys, D. Science 2006, 312, 237.

(63) Tejero, I.; Garcia-Viloca, M.; González-Lafont, À.; Lluch, J. M.; York, D. M. J. Phys. Chem. B 2006, 110, 24708.

(64) Huskey, W. P.; Schowen, R. L. J. Am. Chem. Soc. 1983, 105, 5704.

(65) Ostovic, D.; Roberts, R. M. G.; Kreevoy, M. M. J. Am. Chem. Soc. 1983, 105, 7629.

(66) Saunders, W. H. J. Am. Chem. Soc. 1985, 107, 164.

(67) Arcus, V. L.; Prentice, E. J.; Hobbs, J. K.; Mulholland, A. J.; Van der Kamp, M. W.; Pudney, C. R.; Parker, E. J.; Schipper, L. A. Biochemistry 2016, 55, 1681.

(68) Hobbs, J. K.; Jiao, W.; Easter, A. D.; Parker, E. J.; Schipper, L. A.; Arcus, V. L. ACS Chem. Biol. 2013, 8, 2388.

(69) Dewar, M. J. S.; Zoebisch, E. G.; Healy, E. F.; Stewart, J. J. P. J. Am. Chem. Soc. 1985, 107, 3902. 


\section{TOC Graphic}

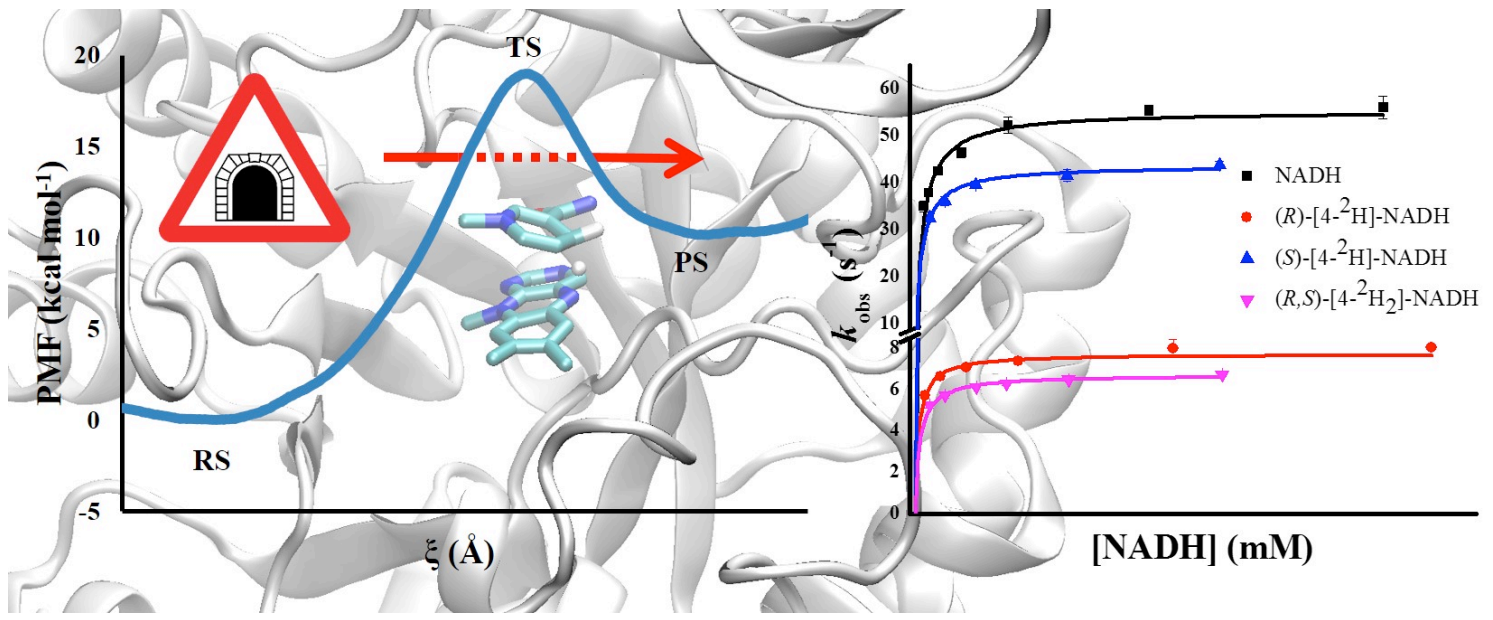

